\title{
GOIÂNIA E OS DIÁLOGOS (RE)PRODUTORES DE UM “CORPO HÍBRIDO”
}

\author{
GOIÂNIA AND THE (RE)PRODUCTIVE DIALOGUES OF A "HYBRID BODY”
}

\section{GOIÂNIA Y LOS DIALOGOS (RE)PRODUCTORES DE UN “CUERPO HÍBRIDO”}

\author{
Marcelo de Mello - Universidade Estadual de Goiás - Anápolis - Goiás - Brasil \\ ueg.marcelo@gmail.com
}

\begin{abstract}
Resumo
Goiânia foi construída para redefinir a lógica gestora do território goiano. Ela foi erguida para romper com os nexos definidos pela oligarquia local e consolidar uma articulação com a economia sediada no sudeste do país. A nova capital foi o elemento central de um discurso universalizador, que anunciava as benesses advindas da instauração de uma nova mentalidade produtiva no estado de Goiás. Entretanto, apesar da eloquência com que a nova capital era anunciada, vários elementos não inseridos no projeto original foram surgindo. Esses elementos representam as demandas particulares presentes na vida dos migrantes convocados a trabalhar na construção da importante obra. Desta forma, a universalidade exaltada pelos discursos oficiais acabou dialogando com a particularidade derivada de ações "coadjuvantes". Esse movimento afetou a forma originalmente delineada para nova capital. Certamente, a modificação na aparência da cidade é um indício de alteração, também, em sua essência. Nesse contexto, uma cidade pautada na "razão" passou a revelar traços de "loucura".
\end{abstract}

Palavras-chave: cidade, universal-particular, aparência-essência, razão-loucura.

\section{Abstract}

Goiânia was built to redefine the administrative logic of the Goiano territory. It was raised to break up the connections defined by the local oligarchy and consolidade an articulation with the economy based on the country's southeast. The new capital was the central element in a universalizing discourse which announced the benefits brought about by the instauration of a new productive mentality in the State of Goiás. However, despite the eloquence with which the new capital was promoted, several elements which were not inserted in the original project started to emerge. Such elements represent the particular demands present in the lives of the migrants who were enlisted to work in the construction of such an important edifice. Thus, the universality promoted by the official discourses ended up interacting with the particularity derived from "supporting" actions. Such movement affected the originally-delineated form of the new capital. Certainly, the modification in the city's appearance is evidence of alterations also in its essence. In such context, a city built upon principles of "reason" ended up revealing traces of "insanity."

Key words: city, universal-particular, appearance-essence, reason-insanity.

\section{Resumen}

Goiânia fue construida para redefinir la lógica gestora del territorio goiano. Ella fue erguida para romper con los nexos definidos por la oligarquía local y consolidar una articulación con la economía localizada en el sudeste del país. La nueva capital fue el elemento central de un discurso universalizador, que anunciaba las ventajas adquiridas de la instauración de una nueva mentalidad productiva en el Estado de Goiás. Entretanto, además de la elocuencia con que la nueva capital era anunciada, varios elementos no inclusos en el proyecto original fueron surgiendo. Estos elementos representan a las demandas particulares presentes en la vida de los migrantes convocados a trabajar en la construcción de la importante obra. De esta forma, la universalidad exaltada por los discursos oficiales terminó dialogando con la particularidad derivada de acciones "coadyuvantes ". Este movimiento afectó la forma originalmente delineada para la nueva capital. Ciertamente, la modificación en la 
apariencia de la ciudad es un indicio de alteración, también, en su esencia. En este contexto, una ciudad pautada en la "razón" pasó a revelar trazos de "locura".

Palabras clave: ciudad, universal-particular, apariencia-esencia, razón-locura.

\section{Introdução}

Na década de 1930 teve início um processo de revisão das bases conceituais sustentadoras da estrutura política, econômica e territorial do estado de Goiás. Tal processo não emerge como resposta às demandas sociais inerentes à vida dos goianos, e sim como uma ação orquestrada por agentes interessados na consolidação e na expansão da estrutura industrial instalada no sudeste do país, sobretudo no estado de São Paulo.

As transformações advindas desse movimento situaram Goiás na periferia de um sistema produtivo engendrado para adquirir abrangência nacional e, nesse contexto, o território goiano foi capturado e reestruturado sob auspiciosos argumentos modernizadores, carregados de virtudes emancipadoras. Estava em curso um processo de redefinição territorial, com vistas à abertura dos caminhos imprescindíveis para a implementação de um arranjo produtivo articulado nacionalmente.

Os discursos enunciadores dessas mudanças ressaltavam as benesses que "naturalmente" decorreriam do movimento renovador. Entre os protagonistas das narrativas que abriram os caminhos imprescindíveis para a redefinição das bases produtivas do território goiano destacamos dois, pela posição que ocupam no imaginário da população do estado de Goiás: o primeiro é o interventor Pedro Ludovico Teixeira, conhecido por "romper" com a estrutura oligárquica no estado de Goiás; o segundo é o "elemento" privilegiado pelo discurso do próprio interventor, batizando, com o nome de Goiânia, a nova cidade capital do estado de Goiás.

Podemos dizer que Goiânia nasce como elemento de um discurso "mudancista", para tornar-se, ela própria, uma produtora de discursos. A nova sede administrativa estadual adquire vida no imaginário dos goianos e assume, a princípio, a forma de uma "filha moça", ${ }^{1}$ repleta de virtudes intrínsecas a uma ação renovadora, fundada numa base racional até então não experimentada pela população de Goiás.

Assim, uma concepção de organismo, formulada na esteira da revolução epistemológica protagonizada por Darwin,${ }^{2}$ foi utilizada para nutrir, no inconsciente coletivo dos goianos, a "moça" gerada a partir da ação planejadora do interventor e médico Pedro Ludovico. A materialização 
desse planejamento assumiu a forma e o corpo de uma cidade. A nova cidade capital foi, em um primeiro momento, produto de uma "idealização higienizada", restrita a gabinetes e escritórios de engenharia e arquitetura. Contudo, o processo de corporificação dessa menina rompeu com os limites dos gabinetes "pasteurizados", promovendo a incorporação de uma diversidade de influências advindas de migrantes operários oriundos de distintos lugares.

Se, portanto, uma disciplina científica moldou, no campo das ideias, o novo núcleo urbano destinado a ser a sede administrativa do Estado, as ações que materializaram a nova capital não puderam ser isoladas das demandas e dos desejos trazidos pelos migrantes construtores de Goiânia. Partindo desse pressuposto, elaboramos a seguinte afirmação: se o entendimento das referências teórico-metodológicas definidoras dos traçados urbanos originais de Goiânia solicita rigor para uma apreensão criteriosa do espírito científico da época, o processo que sucede essa etapa impõe, além do rigor da razão disciplinada, um quesito nem sempre cogitado em pesquisas pautadas em bases científicas: certa sensibilidade.

A sensibilidade por nós indicada é a apresentada por Maffesoli (1998) em seu "elogio da razão sensível". Para ele, perceber que "cada coisa é sua própria interpretação é tão indispensável quanto mais se esteja consciente da polissemia da realidade social e natural” (p. 115). Entretanto, uma percepção polissêmica é frequentemente inviabilizada por métodos aplicados sob a premissa de uma racionalidade instrumental (Hokheimer; Adorno, 1985), de um totalitarismo da racionalidade (Santos, 2004).

Ao investigar o processo de reprodução da nova capital do estado de Goiás, percebemos que os gabaritos, compassos e transferidores utilizados no delineamento de seu sítio urbano original não estiveram presentes na edificação de todos os prédios, bem com na abertura de todas as ruas da cidade capital transformada em metrópole. Entendemos que a razão, como apregoaram os iluministas, é um atributo humano fundamental. Todavia, o "exercício" dessa faculdade humana não traz consigo a obrigatoriedade de um universalismo exacerbado, voltado mais para as demandas de um mercado homogeneizador, do que para a compreensão de realidades constituídas, também, por particularidades inalienáveis e sistematicamente negadas.

Nesta perspectiva, buscando uma postura conjugadora das dimensões universais e particulares, numa empresa dedicada à compreensão 
do processo de (re)produção da cidade-capital erguida na gestão de Pedro Ludovico, partimos da premissa de que Goiânia, a "moça" corporificada a partir da ação discursiva do interventor goiano da "revolução" de 1930, é hoje - e sempre o foi - produto de um movimento semanticamente sobreposto: seu desenho urbano original reproduziu um modelo disciplinador oriundo das terras europeias no Cerrado brasileiro, com o fito de viabilizar o avanço de uma modernização exigida, sobretudo, por agentes paulistas. ${ }^{3}$ Entretanto, no momento em que o projeto é inserido no território, iniciava-se um movimento dissonante entre as ideias e as ações, entre o discurso e a prática. A insurgência de tal discrepância ganha visibilidade nos canteiros de obra, nos quais emergem redes de relações constituídas pelos migrantes operários construtores da nova capital. Estes não compreendiam a lógica hegemônica em curso. Suas ações, como moradores de uma cidade em construção, eram balizadas por necessidades fundamentais, tais como moradia, alimentação, saúde, entre outras, muitas vezes incompatíveis com os imperativos das disciplinas territoriais em processo de implementação. Tal incompatibilidade foi territorializada e alterou os desenhos projetados.

Ressaltamos, ainda - reforçando a conjugação das dimensões universais e particulares -, que o projeto original da cidade capital goiana não foi "morto" ou "soterrado" pelas ações dos migrantes. Pelo contrário, ele continua "vivo" e sendo incessantemente reproduzido pelo território, por meio de empreendimentos inseridos no espaço urbano com a intenção de fazer ecoar, no século 21, a força dos discursos proferidos por Pedro Ludovico Teixeira na década de 1930. Como exemplo, apontamos o debate em torno da definição do lugar mais adequado para a fixação da estátua de Pedro Ludovico Teixeira em Goiânia, no início da segunda década do século $21 .^{4}$

O intenso debate sobre a localização do referido monumento revela a reprodução dos discursos de outra época. Discursos atualizados de diversas formas, e não somente por meio de palavras proferidas em palanques erguidos. No contexto aqui contemplado, evidenciamos os discursos promovidos mediante uma composição semântica pautada em objetos fincados no corpo de uma "menina" corrompida por uma discrepância valorativa, impregnada tanto em seu substrato material como em sua constituição simbólica. Uma discrepância a ser cartografada não com a intenção de posicionar elementos sem vida a partir de referências latitu- 
dinais e longitudinais, mas com o objetivo de situar e contextualizar uma vida reproduzida por relações repletas de representações territorializadas, que desafiam as visões de mundo calcadas em racionalidades instrumentais, lineares e totalitárias (Mello, 2009).

Nesse ponto, entendemos ser oportuna a elaboração de indagações que tratem do processo de corrupção que tomou de assalto o corpo urbano-juvenil da nova capital:

- É possível vincular a perda da virtude original da nova capital a um pecado, também original, comprometedor da materialização dos ideais representados por Pedro Ludovico?

- Ou uma reflexão geográfica dos fluxos corruptivos pode, de alguma maneira, revelar que o pecado original - se este existir - é anterior ao próprio planejamento da cidade capital goiana e tem suas raízes fincadas em um purismo epistemológico derivado de uma racionalidade instrumental, voltada para a produção de um homem unidimensional (Marcuse, 1997), que deve aceitar os papéis oferecidos pelos agentes de uma ordem predeterminada?

Responder às indagações formuladas coloca-nos diante de questões que atravessaram os tempos e os espaços da Renascença e do Iluminismo e avançaram para o século 21. Por essa razão, evocamos a mais clássica tradição geográfica e damos relevo ao diálogo travado entre a aparência e a essência. Desta forma, colocamos de maneira sobreposta dois pares secularmente presentes no debate epistemológico da Geografia, bem como das demais ciências humanas, biológicas e exatas. O primeiro par antitético já foi anteriormente evocado neste artigo: o universal e o particular; o segundo, fazendo coro com o primeiro, foi destacado neste mesmo parágrafo: a aparência e a essência.

Sustentados por esses elementos conceituais, investigamos os discursos materializados a partir da cidade filha de Pedro Ludovico Teixeira e de milhares de anônimos reprodutores da realidade percebida por meio da atual metrópole goianiense. Cabe mais uma vez ressaltar uma preocupação teórico-metodológica: o percurso trilhado não colocou em polos opostos aparência e essência, ou as dimensões particulares e as universais. Pelo contrário, empreendemos um esforço teórico-empírico centrado na integração de uma realidade reproduzida territorialmente. Realidade percebida muitas vezes de maneira fragmentada, comprometendo a com- 
preensão de um movimento dialético alimentado por contradições que mais aproximam os elementos que os distanciam. É o que veremos a seguir.

\section{As "palavras e as coisas" no processo de reprodução de um território urbano}

Foucault (1995) contribuiu de maneira consistente para os estudos dedicados a uma compreensão da realidade que escapa das ditaduras do esquadro e do transferidor. O pensador transpôs as fronteiras predeterminadas que restringem as percepções da realidade, a partir de um mergulho semântico no interior das relações produzidas entre "as palavras e as coisas".

Na obra em questão, há um redimensionamento do entendimento do homem, a partir da superação das fronteiras que condicionam a apreensão de objetos a suas extensões materiais. Ensina o filósofo que a representação não pode se fundar unicamente na estrutura captada pelos olhos. Ela deve, sim, abrir caminhos para o diálogo do visível com o invisível, em um espaço de coexistência, no qual a dimensão empírica da realidade será produzida por um homem atribuidor de sentidos aos objetos.

Portanto, as palavras não podem limitar as coisas, a aparência não pode restringir a essência e o universalmente percebido não prescinde de particularidades que lhe dão "forma". Um conhecimento produzido pelo homem estabelece, como fundamento, que este penetre e dê sentido a um "mundo" de coisas, entre elas, as produzidas pelo próprio homem. Caso contrário, serão as coisas as atribuidoras dos sentidos da vida do homem, e não o inverso.

Essas são as bases sustentadoras dos argumentos aqui apresentados. Não podemos aceitar que os desenhos idealizados para uma cidade definam a priori a dinâmica da vida do homem que a habita. Não pode ser uma cidade o ente que, em um monólogo, determina a personalidade de toda uma sociedade.

Devemos perceber a densa relação firmada entre os objetos territorializados e os homens territorializadores. Não podemos deixar de ressaltar a presença fortalecida de processos de reificação, ${ }^{5}$ em que o homem muitas vezes assume o papel de mera coisa territorializada. Na realidade, é essa instabilidade relacional a produtora de infinitas possibilidades num contexto semanticamente ilimitado, em que estados de "loucura" e de "razão" travam um diálogo denso. 
Da construção do discurso à reprodução da realidade

No livro Memórias, Pedro Ludovico Teixeira (1973) atribui o tímido progresso percebido no estado de Goiás à não existência de "um centro urbano com todos os elementos necessários para se expandir e estimular as múltiplas atividades que caracterizam a vida econômica e social de um povo" (p. 80).

A superação da condição de atraso que caracterizava o estado de Goiás foi condicionada à construção de uma cidade moderna, destinada a impulsioná-lo para um progresso contínuo. Oficialmente, a primeira voz a se erguer publicamente indicando a necessidade de transferência da capital do estado foi a de Carlos Pinheiros Chagas, em um discurso proferido logo após a chegada, no território goiano, das notícias que davam conta da vitória dos "revolucionários" de 1930. Certamente essas palavras não agradaram aos moradores da ex-Vila Boa, antiga capital goiana, local onde o discurso foi proferido.

Com a vitória do movimento "revolucionário", Pedro Ludovico Teixeira foi nomeado interventor e assumiu o Governo estadual. No dia 20 de dezembro de 1932, foi publicado o decreto com a nomeação da Comissão constituída "para proceder aos estudos necessários à escolha de um local para se edificar a futura capital" (Arrais, 2004, p. 105). A comissão percorreu as localidades de Bonfim, Pires do Rio, Ubatan e Campinas, sendo esta última considerada a mais adequada para dar suporte à construção da nova capital.

Destacamos, a seguir, o trecho de uma correspondência escrita pela Comissão. A carta, destinada ao Interventor do Estado, evidencia os esforços para a consolidação de um pensamento mudancista na década de 1930 e faz coro com as ideias de Pedro Ludovico Teixeira apresentadas no início deste tópico:

Antes, porém, de entrar na análise dos vários elementos de que dependem a vida e a expansão de um centro urbano, devo dizer-vos o que penso com relação à oportunidade da mudança da capital de Goiás, problema que sobremodo vos preocupa e é debatido por todos os que se interessam pelo futuro de vosso Estado, cujas riquezas extraordinárias ainda não puderam ser exploradas por vários motivos, entre os quais figura o de não ter ainda aí surgido uma cidade moderna. (Teixeira, 1973, p. 78-79) 
Esse "consenso" em torno da transferência da capital goiana revela a força dos argumentos que atrelavam a modernização da estrutura produtiva do estado de Goiás à construção de uma cidade-capital instauradora de um progresso a ser difundido pelo território. Todavia, esse movimento fez mais do que indicar o que deveria ser construído. Ele apontou, também, para o que deveria ser destruído. Neste sentido, qualquer proposta que não reafirmasse o rompimento com o regime oligárquico era firmemente combatida.

Nesse movimento repleto de conceitos previamente valorados, a estrutura urbana tortuosa da ex-capital, Vila Boa, foi vinculada a uma ideia de atraso incompatível com as benesses de um porvir respaldado por uma razão planejadora, posta a serviço de uma sociedade possuidora dos elementos requisitados para sua evolução. A tradição, representada pelo modelo oligárquico gestado na ex-capital, passa a ocupar o papel de vilã no interior de uma narrativa maniqueísta. Esse atraso, associado à imagem da antiga capital do estado, foi responsabilizado pela condição de penúria e submissão que assolava a vida da maioria dos goianos.

Os discursos de Pedro Ludovico Teixeira - e de outras lideranças políticas da época - combatiam a condição de isolamento em que se encontrava o estado, vinculando-a à estrutura oligárquica presente até a vitória da "revolução" de 1930. O isolamento passou a ser associado ao estado de subalternidade experimentado pelos goianos. Portanto, a instauração de um regime emancipador exigia a aceitação de um movimento integrador, a ser deflagrado a partir da construção da nova capital.

Analisemos o discurso de Pedro Ludovico Teixeira proferido na inauguração da cidade de Goiânia:

Meus senhores. Bastou que novos rumos se dessem à política nacional, novas diretrizes se lhe imprimissem, para que um mundo novo se abrisse diante de nós e nos convencesse de que havíamos descurado muito do que Deus nos tinha dado. Uma nova mentalidade, um grande anelo se formou de bem servir a coletividade, e nosso espírito, habituado, até então, mais a interesses egoístas, de grupos ou de facções, se imbuiu da necessidade de realizar um grande ideal a favor do Brasil. [...] Goiás sentiu também os eflúvios desse despertar. Livrou-se do ópio que o tornava inerte e improdutivo e exitou-se também como o novo estimulante que o tocara. Suas forças estuantes de seiva se movimentaram, conquanto ainda não tenham sido aproveitadas senão em mínima parte do seu potencial. Mesmo assim, novas perspectivas se nos defrontam e, dia a dia, 
mais alvissareiras. Um sopro de vida, de entusiasmo, percorre este Estado mediterrâneo em todos os quadrantes. Há um anseio de trabalho, de produção, de organização, de melhoria em todas as formas da atividade humana. [...] Terminando a minha breve oração, cumpro o dever de vos transmitir os meus ardorosos agradecimentos pela gentileza da vossa vinda a esta Capital, cidade nova, em que nada podeis ver que vos surpreenda, que vos impressione, a não ser o imenso esforço de quem a construiu. Desejo, servindo-me de uma expressão do Dr. Paulo Figueiredo, que não a vejais apenas, mas a compreendais. (Teixeira, 1973, p. 216-217)

Vamos atender ao pedido feito por Pedro Ludovico Teixeira: compreender Goiânia. Compreender uma cidade-capital construída para romper com uma lógica reacionária e viabilizar a implantação de um nexo "revolucionário". Um nexo "revolucionário" caracterizado não por propor uma redistribuição mais justa das riquezas produzidas no estado, mas por aproximar Goiás das demandas apresentadas pelo Sudeste brasileiro.

A revolução proposta por Pedro Ludovico Teixeira é centrada em Goiânia, nos traçados das ruas e nos contornos das praças presentes do projeto original. Ele geometrizou o espaço urbano, estabelecendo um ordenamento pela via da linguagem matemática. Essa foi a grande revolução promovida por Pedro Ludovico Teixeira: uma revolução discursiva, sustentada por uma racionalidade instrumental, produzida em forma de cidade disciplinadora. A nova capital deveria espargir pelo estado a nova mentalidade produzida a partir da "revolução" de 1930.

\section{Goiânia e os limites revelados pelos Tristes Trópicos}

Lévi-Strauss, um dos mais importantes pensadores do mundo moderno, visitou as obras de construção da nova cidade-capital do estado de Goiás em 1937. Suas considerações destacaram seu espanto com a construção de uma cidade em um lugar tão ermo e vazio. O antropólogo comparou as precariedades presentes nos canteiros de obras com os trabalhos realizados em campos de batalha. Talvez o que não tenha sido percebido pelo importante pensador francês é que se tratava realmente de um campo de batalha, de um conflito travado entre duas perspectivas: de um lado, as representações modernas erguidas em "solo inóspito", anunciando as possibilidades inerentes a uma noção de progresso calcada em uma racionalidade universal e modernizadora; de outro, a tradição sustentada por 
uma oligarquia responsabilizada pelo estado de padecimento material e existencial da população goiana.

As contradições percebidas pelo antropólogo europeu podem servir para fortalecer o discurso de Pedro Ludovico Teixeira: se para Lévi-Strauss havia uma incompatibilidade entre a geometria da cidade moderna e o tortuoso ambiente do Cerrado, para os goianos crentes nos discursos do interventor, a incompatibilidade residia na aceitação da condição de atraso, quando era possível a produção de uma nova realidade.

Nesse contexto, a instauração do "novo" estava para além de uma meta abstrata, pois se tornou uma obrigação a ser cumprida, sob a forma de uma cidade repleta de apelos valorativos. Assim, as características territoriais e ambientais goianas, classificadas pejorativamente, não eram vistas como limitadoras, mas como incentivo à superação do estado de atraso.

As virtudes do povo goiano seriam comprovadas pela redefinição de seu modo de vida. É como se vislumbrássemos no Cerrado goiano a produção das condições materiais e simbólicas apresentadas por Lefebvre no seu $O$ direito à cidade (1991). Nessa obra, o autor trata do processo de urbanização, evidenciando sua complexidade. Como afirma Chaveiro (2001), naquela época a cidade ainda era o "lugar desejado".

Tal desejo conduziu milhares de migrantes aos canteiros de obras que fizeram brotar a nova capital. Esses operários "incultos", com suas enxadas, serrotes, martelos e carros de boi, materializaram as condições imprescindíveis à penetração efetiva de uma ideia de progresso no território goiano. Os "ventos da modernidade" alcançaram o estado de Goiás por meio da ação de migrantes desconhecedores das verdadeiras intenções guiadoras de seus trabalhos.

Tratava-se, certamente, de uma condução alienadora. Os operários-migrantes, concomitantemente, participavam e estavam alheios do processo, não compreendendo a verdadeira natureza orquestradora das ações em curso. Contudo, alguns questionamentos mostram-se relevantes para o entendimento de um cenário tão complexo: em que medida os agentes da ordem oficial revelavam uma consciência plena de todo processo em curso? E, ainda mais importante, o estado de alienação dos operários não deve ser limitado à percepção guiada pelo projeto oficial? Será que a alienação a eles atribuída não esconde uma consciência marginal, produtora de ações contestadoras da vontade hegemônica que, a princípio, motivou a construção de Goiânia? 
Neste momento, respeitando as distâncias que separam as obras, $O$ Direito à Cidade, de Lefebvre (1991) e Espaços de Esperança, de Harvey (2004), questionamos: como a cidade do direito e do desejo tornou-se um espaço que requisita uma esperança demandada por sociedades modernas que experimentam uma profunda crise urbana? Se na época da construção de Goiânia, visitada pelo antropólogo francês, vigorava o desejo à cidade e hoje temos a crise da cidade - inclusive da cidade de Goiânia -, não seria necessário questionar se estados classificados como de alienação e consciência, distintamente avaliados, corroboraram para a instauração da crise urbana?

Essa indagação deve-se ao fato de uma cidade planejada - no bojo de um movimento guiado pelo sistema capitalista de produção - apresentar uma característica fundamental: ela é produto de um projeto segregador, certamente velado. Mas seria possível a aceitação prévia de uma segregação por parte do sujeito segregado? No outro extremo, poderíamos sequer imaginar o segmento hegemônico aceitando e respeitando um estado de consciência revelado pelo migrante-operário, portador de necessidades contrárias a seus interesses? Nesse contexto, os que não compartilham o estado de consciência forjado a partir das demandas do segmento hegemônico são considerados alienados, ignorantes e carentes da coerência conquistada pelos que exercitam uma racionalidade instrumentalizada. Afinal, não seria interessante um julgamento que atribuísse ao "diferente" qualquer tipo de consciência!

Para desvendar esse processo é imprescindível dar a palavra a "todos" os sujeitos dessas histórias territorializadas. No que se refere aos discursos oficiais, as palavras transcritas nos tópicos anteriores expressam, com clareza, a visão de mundo hegemônica. Cabe, agora, apresentar elementos reveladores da existência de uma consciência por detrás de uma alienação migrante previamente qualificada.

Para tanto, dialogamos com uma das pioneiras de Goiânia. Entrevistamos uma mulher que participou ativamente do processo de construção da nova capital. Certamente, nossa entrevistada teve sua vida afetada pelos pronunciamentos oficiais dos gestores públicos daquele tempo. Mas sua relação com a cidade transcendeu as falas dos responsáveis pela apresentação de um projeto modernizador. Dona Elízia acompanhou vidas redefinidas por uma cidade que, por sua vez, teve seu projeto alterado por migrantes atraídos pelas promessas dos agentes públicos. A realidade 
descrita pela pioneira revela uma polissemia inalienável no diálogo entre as dimensões universal e particular.

\section{Considerações finais}

Dona Elízia foi uma das migrantes responsáveis pela construção de Goiânia, para onde se mudou no ano de 1937. ${ }^{6}$ Suas ações deram origem a um comércio nas proximidades do córrego Botafogo. Ela também foi a responsável por "campear" os alunos da primeira escola daquela região da cidade em construção. Se os olhos de Lévi-Strauss perceberam uma contradição escandalosa entre a tortuosidade e as agruras do ambiente do Cerrado, quando comparado com o traçado simétrico das ruas que estavam sendo abertas; e entre a precariedade das ferramentas utilizadas na construção, quando confrontadas com o fino acabamento exigido pela Art déco, o relato de nossa entrevistada revela que seus olhos de migrante registraram outras impressões.

Isso porque, segundo Dona Elízia, ${ }^{7}$ os chegantes no território da nova capital nunca tinham experimentado um movimento tão intenso nos seus lugares de origem ou de passagem, enquanto as ferramentas "precárias” e os veículos a tração animal eram, para eles, comuns e profundamente simpáticos. E, o principal, a possibilidade de ingresso de seus filhos em grupos escolares era uma oportunidade impensada até então, da mesma forma que a assistência médica era uma realidade muito mais próxima na nova capital do que no lugar de nascimento dos migrantes.

Nessa perspectiva, seria interessante focar o processo em curso, ressaltando o movimento inalienável nele inserido. Massey (2008) adverte sobre os limites presentes em visões de mundo pautadas em um estruturalismo que imobiliza o espaço para compreendê-lo. Um espaço congelado não poderia realmente evidenciar as transformações que estavam ocorrendo.

Com certeza, a velocidade das transformações goianas não podia ser comparada com as movimentações manifestadas em São Paulo ou em Paris. Contudo, os olhos dos migrantes percebiam as alterações produzidas. Isso era ressaltado pelos jornais e rádios da época. Estava sendo processada uma modificação na mentalidade dos envolvidos na construção da cidade-capital: a densa estrutura oligárquica estava em dissolução, dando lugar a um novo arranjo político-territorial pautado numa integração produtiva. 
A nova cidade de Pedro Ludovico Teixeira foi um marco na composição dessa nova mentalidade. Ela foi erguida para se tornar o discurso enunciativo de um novo tempo, no qual a integração, a articulação e o movimento revigorador sucederiam ao isolamento asfixiante, produtor de uma servilidade posta a serviço de "coronéis".

Esses pressupostos indicam a necessidade de calibrar o olhar lançado por sobre a paisagem urbana. Uma postura criteriosa é imprescindível ao processo de produção do conhecimento, para não desconsiderarmos os movimentos reprodutores do mundo percebido pelos sentidos. Como ensinam Santos (2004), Moreira (1987) e Gomes (1996), entre outros, a paisagem é uma categoria de grande importância nas investigações científicas destinadas ao estudo do espaço produzido pelo homem. Contudo, essa importância não se encerra nela mesma. A paisagem destaca-se quando é colocada em movimento pela comparação com outros recortes do espaço em tempos diferentes.

Santos (2004) afirma que, com a paisagem, apreendemos a simultaneidade de tempos desiguais em uma escala espacial definida. Assim, quando a paisagem é colocada em movimento na ação investigativa, muitos processos e objetos camuflados são revelados, muitos mecanismos ocultos são identificados e tornam-se passíveis de avaliações.

Os olhos da Sra. Elízia acompanharam por setenta e quatro anos o movimento instaurado a partir da nova capital; seus ouvidos capturaram narrativas de pessoas em movimento, de migrantes que na década de 1930 pactuaram com Goiânia um contrato social para a promoção de uma nova realidade. Um movimento indiscutivelmente aliado a um projeto universalizador se processava. Entretanto, a dimensão universal não torna tal projeto homogêneo. Pelo contrário, os caminhos percorridos por goianos e migrantes sequiosos por embarcar nesse movimento são particulares.

E a particularidade aqui destacada só poderá ser compreendida se as narrativas margeantes forem contempladas, como propomos neste texto. Lévi-Strauss cumpriu seu papel de intelectual mundial: ele destacou a distância entre realidades arquitetadas a partir de um discurso estrategicamente aproximado. O antropólogo comparou Goiânia em construção com as cidades idealizadas pelo Iluminismo eurocêntrico.

O que nos cabe? Além de outras tantas tarefas, cabe-nos ressaltar elementos percebidos somente pelos que estão inseridos em um movimento marcado, também, por singularidades. Devemos ressaltar as pos- 
sibilidades inerentes à natureza cognitiva do homem. Se somos homens, não o somos unicamente pelos sentidos que temos, mas pelo que nos tornamos a partir do diálogo travado entre a realidade captada pelos nossos sentidos com a nossa cognição. A investigação do processo de reprodução do espaço urbano de Goiânia pode promover uma revisão no posicionamento do sujeito cogniscente. Deste que lança seu olhar para uma cidade e pode animá-la ou desanimá-la; torná-la prenhe de vida ou decretar seu desfalecimento.

\section{Notas}

1. Paulo Figueiredo, redator da Revista Oeste, anuncia Goiânia como a "filha mais moça e bonita do Brasil". Além do artigo, em que qualifica a nova capital como rebenta de um processo capitaneado por Pedro Ludovico Teixeira, o escritor é autor de inúmeros textos favoráveis às ações do interventor do Estado.

2. Naturalista britânico que em 1859 publica A origem das espécies.

3. Nesse momento, estava sendo redefinida a lógica articuladora do território nacional. Até então, os caminhos abertos em todas as regiões não contemplavam um sistema produtivo nacionalmente integrado. Goiânia, Belo Horizonte e Aracaju foram cidades planejadas para atender às demandas dessa lógica em ascensão. Elas romperam com a lógica urbana derivada da colonização.

4. Uma expressiva polêmica esteve presente no processo de escolha do lugar no qual se fixaria a estátua de Pedro Ludovico Teixeira. A Agência Goiana de Cultura defendia que o monumento deveria ser fixado no Morro da Serrinha, local sem grande visibilidade. Outra corrente difusa entendia que o melhor lugar era a confluência das avenidas Goiás e Anhanguera. Contudo, no dia 13 de outubro de 2010, dezenove anos após sua concepção, a estátua acabou sendo colocada na Praça Cívica, ao lado do Palácio Pedro Ludovico Teixeira, sede do governo estadual.

5. Uma forma de alienação na qual as relações sociais são percebidas como "coisas", são coisificadas.

6. No mesmo ano em que ocorreu a visita de Lévi-Strauss.

7. Entrevista concedida no dia 3 de abril de 2011.

\section{Referências}

ARRAIS, Tadeu Alencar. Geografia contemporânea de Goiás. Goiânia: Vieira, 2004.

CHAVEIRO, Eguimar Felício. Goiânia, uma metrópole em travessia. Tese (Doutorado em Geografia). Faculdade de Filosofia, Letras e Ciências Humanas, Universidade de São Paulo. São Paulo, 2001. 
FOUCAULT, Michel. As palavras e as coisas. São Paulo: Martins Fontes, 1995.

GOMES, Paulo C. C. Geografia e modernidade. Rio de Janeiro: Bertrand Brasil, 1996.

HORKHEIMER, M.; ADORNO, T. W. Dialética do esclarecimento. Rio de Janeiro: Jorge Zahar, 1985.

HARVEY, David. Espaços de esperança. São Paulo: Loyola, 2004.

LEFEBVRE, Henri. O direito à cidade. São Paulo: Moraes, 1991.

LÉVI-STRAUSS, Claude. Tristes trópicos. São Paulo: Companhia das Letras, 1996.

MAFFESOLI, Michel. Elogio da razão sensível. Petrópolis, RJ: Vozes, 1998.

MARCUSE, Herbert. Cultura e sociedade. Rio de Janeiro: Paz e Terra, 1997.

MASSEY, Doreen. Pelo espaço: uma nova política da espacialidade. Rio de Janeiro: Bertrand Brasil, 2008.

MELLO, Marcelo de. Brasília e Águas Lindas de Goiás: a loucura e a razão no processo de produção de um território. Tese (Doutorado em Geografia). Instituto de Estudos Sócio-Ambientais, Universidade Federal de Goiás. Goiânia, 2009.

MOREIRA, Ruy. O discurso do avesso: para a crítica à Geografia que se ensina. Rio de Janeiro: Dois Pontos, 1987.

SANTOS, Milton. A natureza do espaço: técnica - tempo/razão - emoção. São Paulo: Edusp, 2004.

TEIXEIRA, Pedro Ludovico. Memórias. Goiânia: Cultura Goiana, 1973.

Marcelo de Mello - Possui graduação em Geografia pela Universidade Federal de Goiás. Possui Mestrado, Doutorado e Pós-Doutorado em Geografia pela mesma Universidade. Atualmente é professor da Universidade Estadual de Goiás, Unidade Universitária da Cidade de Goiás. 